\title{
Pulse TIG welding: Process, Automation and Control
}

\author{
P. K. Baghel*, $\dagger$ and D. S. Nagesh* \\ *Department of Mechanical Engineering, Delhi Technological University, Bawana Road, \\ New Delhi 110042, India
}

†Corresponding author : pushpbaghel.dtu@gmail.com

(Received May 31, 2016 ; Revised September 26, 2016 ; Accepted October 19, 2016)

\begin{abstract}
Pulse TIG (Tungsten Inert Gas) welding is often considered the most difficult of all the welding processes commonly used in industry. Because the welder must maintain a short arc length, great care and skill are required to prevent contact between the electrode and the workpiece. Pulse TIG welding is most commonly used to weld thin sections of stainless steel, non-ferrous metals such as aluminum, magnesium and copper alloys. It is significantly slower than most other welding techniques and comparatively more complex and difficult to master as it requires greater welder dexterity than MIG or stick welding. The problems associated with manual TIG welding includes undercutting, tungsten inclusions, porosity, Heat affected zone cracks and also the adverse effect on health of welding gun operator due to amount of tungsten fumes produced during the welding process. This brings the necessity of automation. Hence, In this paper an attempt has been made to build a customerized setup of Pulse TIG welding based on through review of Pulse TIG welding parameters. The cost associated for making automated TIG is found to be low as compared to SPM (Special Purpose machines) available in the market.
\end{abstract}

Key Words : Pulse TIG welding, Automation, Review, TIG variants

\section{Introduction}

The Tungsten Inert Gas (TIG) welding is a welding process that uses a non-consumable tungsten electrode and an inert gas shield to protect the electrode, arc column and weld pool ${ }^{1)}$ as illustrated in Fig. 1. The weld arc acts as a heat source only and the welding engineer has a choice of whether or not to add a filler wire. Argon or helium is used as shielding gas to protect the weld from atmospheric oxidation. (V-I) characteristics of drooping type is used as power source. In the domain of arc welding processes TIG welding continues its apex position due to its versatility and flexibility in adaptation. The superior weld quality obtained in TIG weldments differentiates the TIG process in comparison with other competing and emerging joining process.

The modified version of TIG welding process is pulse TIG welding process in which pulse current alternates between a low level and peak level. Heating and fusion take place during peak current period and weld pool cooling. Solidification takes place during pulses as the heat is dissipated in the job during the low level current period. This current pulsing leads to intermittent melting along the joint seam giving a series of discrete melt spots, which overlap each other ${ }^{2)}$. Current pulse regulator also adjust for the number of pulse per second and the duration of time spent at the peak current level which leads to control heat input and thus improves

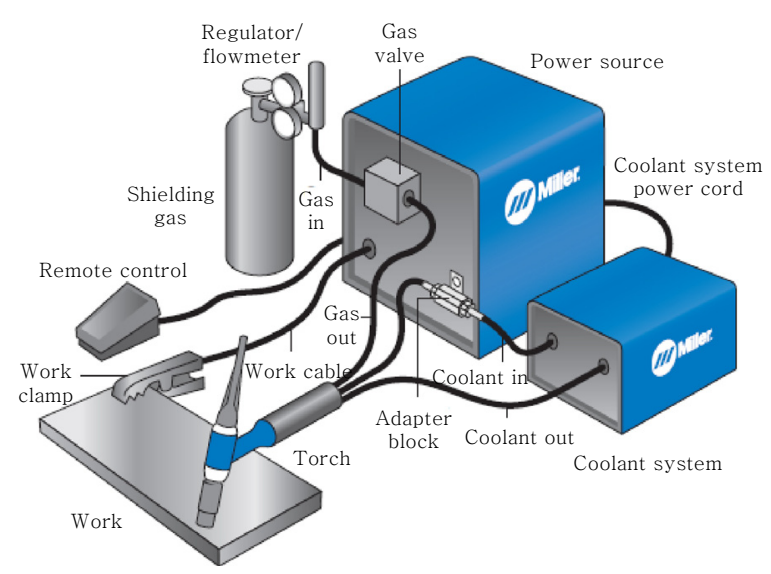

Fig. 1 TIG set-up ${ }^{1)}$ 


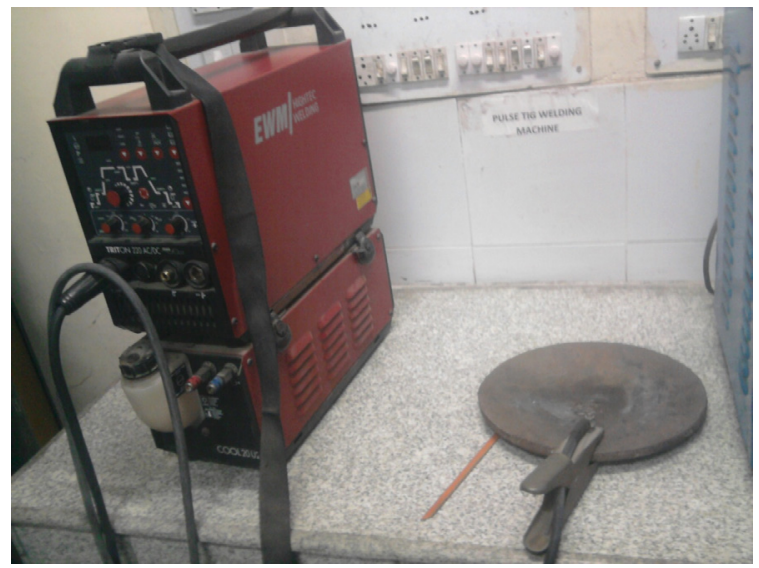

Fig. 2 Pulse TIG welding machine

weld profile. DCEN is preferred current supply. The machine is shown in Fig. 2.

Pulse current characteristics are readily used to control the weld pool formation. High heat accelerates the weld pool formation which reduces the properties as gases from surrounding atmosphere like hydrogen readily diffused in weld pool inducing stress leading to cracks.

Due to controlled heat input, distortion and warpage are minimized specially for dissimilar thickness metal joining. It is also used to join dissimilar metals of same thicknesses such as copper to stainless steel, stainless steel to mild steel.

\section{Machine parameters}

Finding Optimum condition of Pulse TIG welding parameters are useful in metallurgical advantages of weldments. Literature frequently revealed improvement in grain refinement of fusion zone grain size and structure, reduced width of heat affected zone, control segregation because of current pulsing parameters ${ }^{3)}$. The control heat input obtained due to current pulsing decreases the distortion and warpage which helps in improvement of mechanical properties ${ }^{4,5)}$. From the recent literature available it is evident that the welding speed and wire feed rate are not considered as main parameters. The welding speed is proved significant parameter in controlling weld bead characteristics. Faster the welding speed, faster the cooling rate, smaller the grains formed resulting in maximum tensile properties ${ }^{6,7)}$. The automation in welding process is required for superior weld quality at faster speeds. The automation in joining process is the main demand in the industry, but they have certain limitations as compared to semi-automatic system like

- High initial cost: Automated welding systems require higher initial investment. The amount required for setting up automation is estimated around $\$ 175,000$ to $\$ 250,000$ whereas semiautomatic systems often start around $\$ 30,000^{8)}$.

- Zero flexibility: The flexibility of a machine has an inverse relationship with the degree of automation. While semiautomatic machines can be moved from one part to the next, the automatic systems can only make a dedicated and pre-programmed manufacturing operation.

- Longer lead time: Setting and implementing automated welding system requires a longer lead time for reaching full-scale production. If a company needs to begin welding parts immediately, semiautomatic machines takes 4 to 8 weeks to deliver whereas fully automatic system takes at least 20 weeks and therefor takes longer time to outweigh the initial lead $\operatorname{cost}^{9)}$.

- Requirement of expertise in employees: Employees requires training programme for interacting with new robotic equipment. This normally takes time and financial output.

- High preventive maintenance: High preventive maintenance is required in automatic system because of complexity as compared to semiautomatic machines. The maintenance program includes cleaning and lubricating the machine, calibrating the controls and power supply, and replacing consumables.

- Consideration of product life cycle: Automation system does not suite for elements which follow unpredictable pattern of introduction, growth, maturity and decline in product life cycle. Whereas semiautomatic machines are readily used for such type of products. Batteries, sensors, fuel filters, medical components, nuclear devices, pipe fittings, transformer cores etc are products manufactured by semiautomatic systems.

\section{Automation in pulse TIG welding machines}

These are semi-automatic machines built for special purpose. They have several benefits which includes consistency in quality welds, greater repeatability and lowered production costs, fewer scrapped parts, increases return on investment and faster speed per cycle. karpagaraj et al. ${ }^{10)}$ used automatic setup for welding titanium alloy in which torch movement is automated using single axis mechanism. Tadayuki suggested to have built the automatic setup built having torch position specifically kept at $40^{\circ}$ to yield good results ${ }^{11)}$. The block diagram of automation in TIG welding has been given in Fig. 3.

An automatic setup is built to weld dissimilar metals having thickness greater than $6.35 \mathrm{~mm}$. To improve the quality of weld joint automation is essential especially 


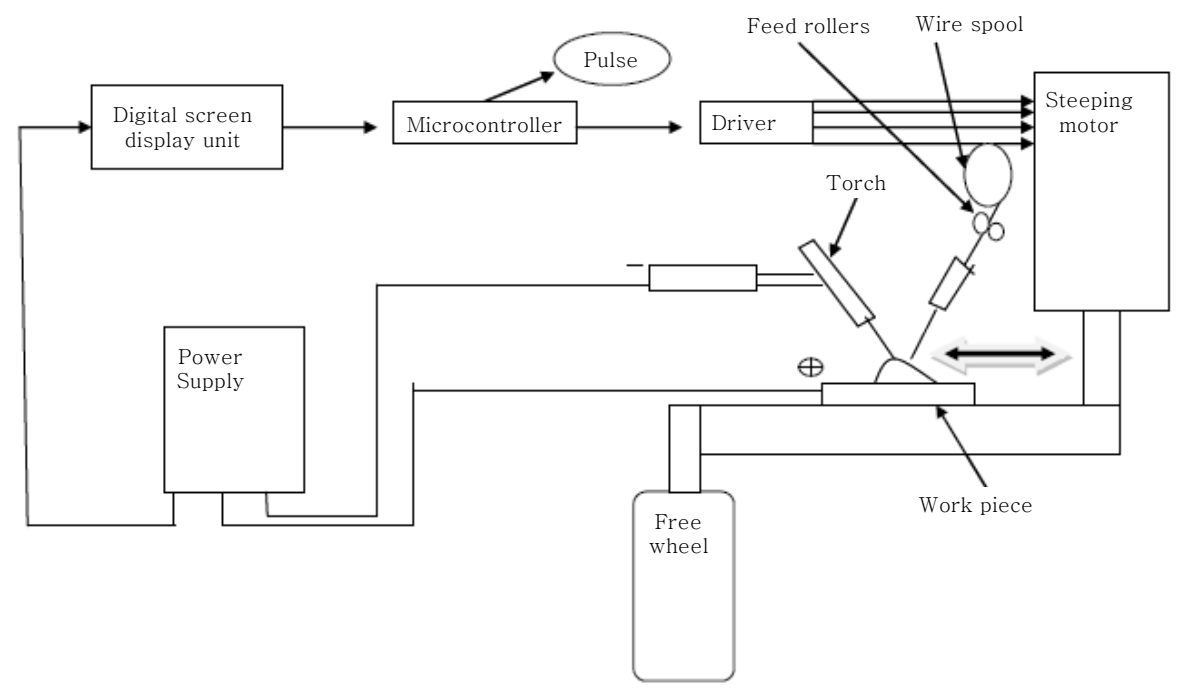

Fig. 3 Automatic TIG setup

where thickness of welding sections are greater than $t>5^{12}$. Also adverse effect on operator health due to amount of tungsten fumes, safety of operator and costly availability of SPM in the market are some of the reasons which urged to make automation in TIG welding process.

\subsection{Automatic Torch movement}

Automating the torch motions decreases the error potential which means decreased scrap and rework. The setup consists of trolley, pencil torch, track, fixture for holding pencil torch. The Weldcraft WP-9P, Light-Duty Front Loading air cooled TIG Pencil Torch for fixture mounted TIG applications is used which has following specifications.

WP-9P Specifications:

- 125 Amp DC, 100 Amp AC (60\% duty cycle)

- Electrode capacity .020" (0.5mm) -- 1/8" (3.2mm)

- Torch body weight $3.0 z(85.0 \mathrm{~g})$

- Torch length 6" (152mm)

- Handle diameter 3/4" (19.0mm)

Roshan et al. ${ }^{13)}$ uses single axis movement of torch us- ing lead screw for welding carburetor components of sheet metal thickness of $1.2 \mathrm{~mm}$. The set up with torch movement is shown in Fig. 4.

\subsection{Automatic Manipulator movement}

In this type of automatic setup movement of workpiece is provided by the manipulator movement and welding torch is held stationary. The stepper motor (Bipolar, 200 Steps/Rev, 42×38mm, 2.8V, 1.7 A/Phase) is used to drive the lead screw shaft on which the manipulator is attached. Block diagram for Stepper motor control system has been shown in Fig. 5.

The input signals receive by stepper motor is in the form of pulses. First the power supply is given to the programmable logic control then it selects the motion data signal and send it to pulse generator for controlling the motion. Then pulse generator directs the pulse signal towards motor driver which converts the pulse signal into electrical signal and send it input terminal of stepper motor. Movement of manipulator is provided by the mechanism as shown in Fig. 6.
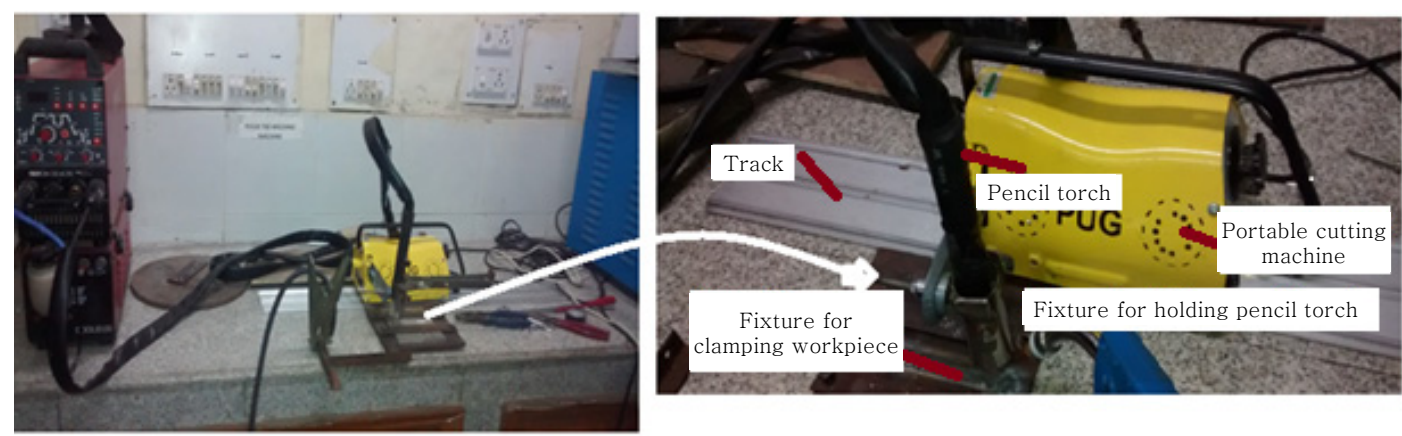

Fig. 4 Torch mounted on trolley moving on dedicated track 


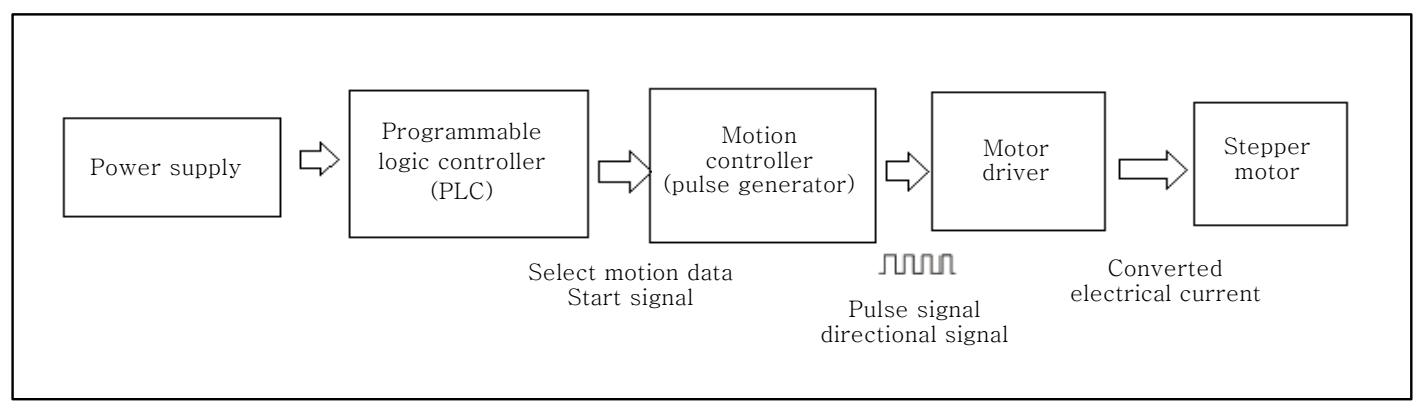

Fig. 5 Block diagram of stepper motor control system

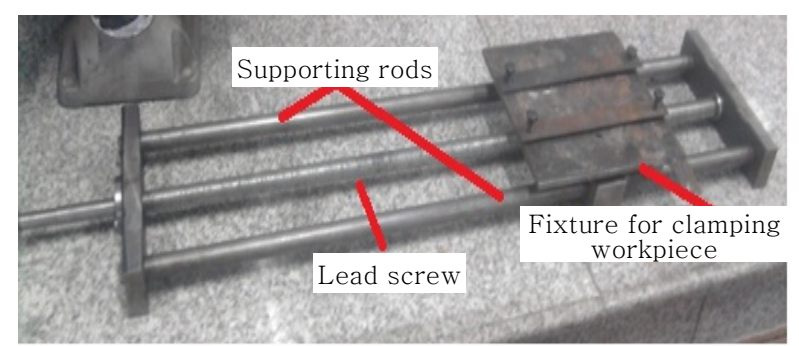

Fig. 6 Single axis driven mechanism

The wire feed system is another part of automation in pulse TIG welding system .Controlling the wire feed rate is essential parameter as it influences cooling rate of weld which effects the grain size and ultimately influences weld metal properties ${ }^{14)}$. Welding done on thickness more than $\mathrm{t}>6 \mathrm{~mm}$ requires wire feeding. When welding dissimilar metal the wire feeding becomes more important as required joint properties are obtained when the composition of filler alloy matches with the dissimilar metals to be joined.

Currently the wire feed system present in the market are MIG wire feeder systems whose cost is $\$ 100{ }^{15}$ ). Thus it is obvious that cost incurred for manufacturing will be much higher. To decrease the cost of welding manufacture the custom made wire feed system is build.

\subsection{Custom built wire feed system}

The custom built wire feeder system comprises of feeder casing, feeder motor (5A, 24V), MIG Torch, Teflon liner, Copper wire Transformer $(5 \mathrm{~A}, 12 \mathrm{~V})$, Silicon bridge rectifier (406KBL), Voltage variac (4A). First the $220 \mathrm{~V}, 50 \mathrm{~Hz}$ power supply was given to voltage variac or dimmer to vary the voltage which leads to change in fire feed rate, then output of voltage variac is given in step down transformer which decreases the voltage as per its rating. The output of decreasing voltage is then given in silicon bridge rectifier which converts ac into dc and finally the dc output is given in the dc wire feed motor. The custom build setup built along with circuit diagram is shown in Fig. 7. The total expenditure occurred was around $\$ 3000$ which is much lesser as compared to feeders available in the market.

Over the years there has been lot of modifications in improving the existing TIG welding techniques. Some recent modifications in TIG welding setup in the form of variants. Some recent variants includes hot wire TIG where resistance heated filler wire is fed into the weld puddle preventing the weld pool from chilling early which allows the filler to flow out across the weld puddle resulting in smooth, attractive weld bead. Arvinda et al. ${ }^{16)}$ studied and compared the mechanical and microstructural properties of modified $9 \mathrm{Cr}-1 \mathrm{Mo}$ welds produced by narrow gap hot wire and cold wire GTAW and results shows that impact properties produced at $0^{\circ} \mathrm{C}$ of 9Cr-1Mo is inferior for hot wire GTAW as compared to welds produced by cold wire GTAW and at $18^{\circ} \mathrm{C}$ toughness is comparable for both hot wire and cold wire GTAW.
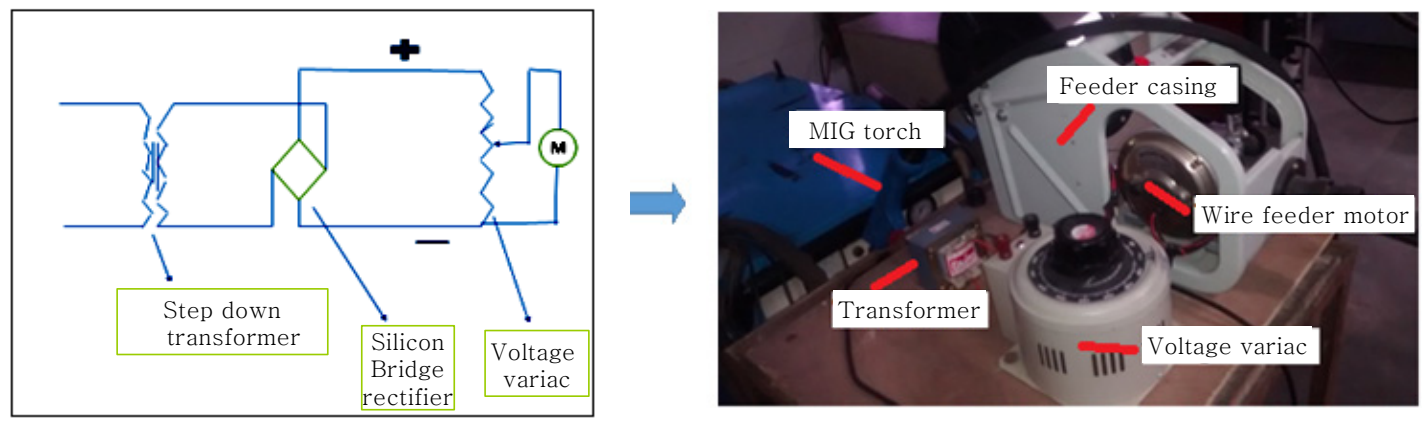

Fig. 7 Circuit diagram of custom built wire feeder and custom build wire feeder for pulse TIG 
Another variant is TIG arc spot welding which is same as conventional TIG except control system which includes timing device and torch nozzle is modified. Morgan et al. ${ }^{17)}$ developed the model to predict heat transfer. The model takes into account Lorentz forces and surface tension effects. The results indicates that multiphysics simulation is useful numerical technique to study the estimated front motion and disturbance caused by sensors.

Twin electrode TIG welding is other variant of TIG. In this the arc is made to strike from two electrodes separately. The two electrodes are moved side by side along the joint to obtain a wide smooth weld without any undercuts. Zhang et al. ${ }^{18)}$ studied the physics characteristics of coupling arc formation. Arc cone shape using CCD camera was observed and arc pressure was measured. The results show that coupling arc includes two arcs that pull each other according to Lorentz force which forms one big coupling. Thus results proves that stable welding process can be achieved by twin-tungsten TIG at higher current than that of conventional TIG because of low arc pressure and high efficiency welding.

Manual programmed TIG welding is another variant where welding is achieved by use of foot controlled rheostat for starting and finishing a weld. A finger switch on TIG torch can be used to select the specific programme to achieve a desired weld. Main applications include welding tube-to-tube sheet and root pass welding in pipe work.

\section{Experimental procedure}

Soft aluminum alloy 5083-O and strain hardened aluminum alloy 6061-T651were used in this study. AA 5083-O Al alloy was placed in the right side and AA 6061-T651 was placed in the left side of the direction of weld as AA 6061 has higher flow strength than AA5083 aluminum alloy). A weld size of $120 \mathrm{~mm} \times 150 \mathrm{~mm} \times$ $6.35 \mathrm{~mm}$ of each was used for fabrication of butt joined
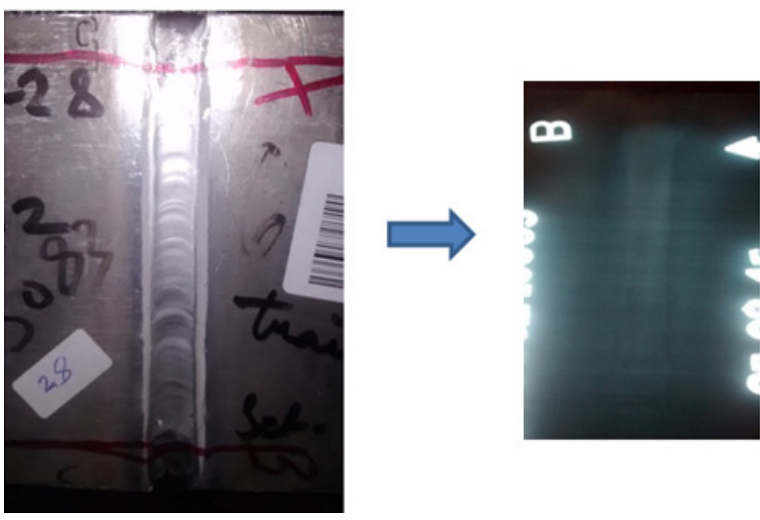

(a)

(b)

Fig. 8 a) Welded plate specimen of 5083-O and 6061T651 b) Radiography

using Pulse TIG welding (Triton 220 AC/DC). Fig. 8 shows welded specimen of 5083-O and 6061-T651 and radiography. Defect free welds are obtained as shown by the radiography film

\subsection{Mechanical Properties}

The tensile samples were extracted from welded samples along the transverse welding direction and prepared as per ASTM E8 M04 standard as shown in fig. 9. Tensile test was carried out in $50 \mathrm{KN}$ eletro-mechanical controlled universal testing machine (Tinius Olsen) with cross head speed of $2.5 \mathrm{~mm} / \mathrm{min}$. The joint exhibits tensile property of $213 \mathrm{MPa}$, yield strength of $176 \mathrm{MPa}$ and elongation of $12 \%$.

\section{Conclusion}

1) Automation of Pulse TIG setup is done to weld dissimilar metals. A customerized setup is build whose manufacturing cost is very low as compared to setup available in the market. This makes it a low cost auto-

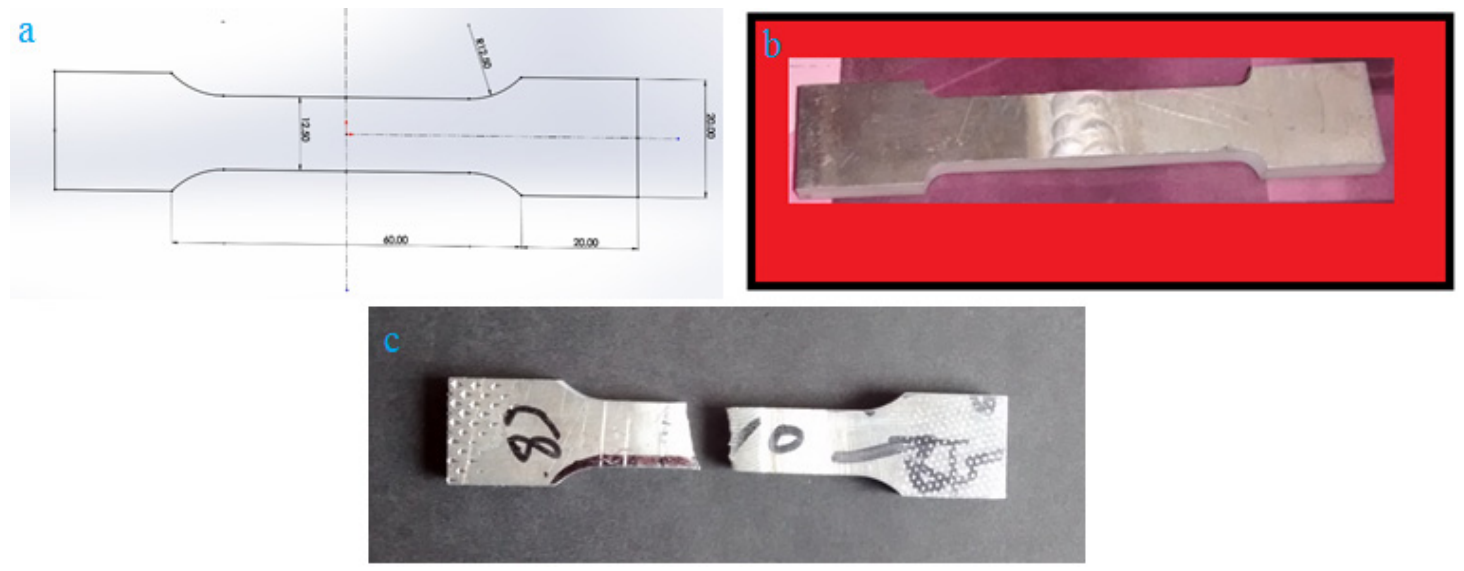

Fig. 9 Shows tensile specimen 
mation of welding process.

2) Recent variants has also been discussed which are automated with few modifications compared to conventional Pulse TIG welding setups. The modifications exclusively made to enable them to be used for particular applications.

3) Defect free weld is obtained as indicated by radiography results.

4) Tensile results exhibits tensile property of $213 \mathrm{MPa}$, yield strength of $176 \mathrm{MPa}$ and elongation of $12 \%$

\section{References}

1. H.B Cary. Modern welding technology (NJ), PrenticeHall, (1989)

2. J. Cornu. Advanced welding system, TIG and related processes. Springer, Heidelberg 3 (1988), 61

3. T Mohandas, R G Madhusudhana, Effect of frequency of pulsing in gas tungsten arc welding on the microstructure and mechanical properties of titanium alloy welds. J Mater Sci Lett, 15 (1996), 626-628

4. V Balasubramanian, V Ravisankar, RG Madhusudan, Effect of pulsed current and post weld aging treatment on tensile properties of argon arc welded high strength aluminum alloy. Materials Science and Engineering A, 459 (2007), 7-18

5. M Balasubramanian, V Jayabalan , V Balasubramanian, A mathematical model to predict impact toughness of pulsed current gas tungsten arc welded titanium alloy, International Journal of Advanced Manufacturing Technology, 35 (2008), 852-858

6. KCW Yunga, B Ralph, WB Lee, R Fenn, An investigation into welding parameters affecting the tensile properties of titanium welds, Journal of Material Processing Technology 63(1-3) (1997), 759-764
7. C Meran, Prediction of the optimized welding parameters for the joined brass plates using genetic algorithm. Material Design, 27(5) (2006), 356-363

8. Trade India catalogue, (2010)

9. BC Howard, CH Scott, Modern Welding Technology. Pearson/Prentice Hall, (2005)

10. A Karpagaraj, NS Shanmugam, K Sankaranarayanasamy, Some studies on mechanical properties and microstructural characterization of automated TIG welding of thin commercially pure titanium sheets, Material Science \& Engineering A, 640 (2015), 180-189

11. T Otani, Titanium Welding technology, Nippon Steel Technical Report, 95 (2007), 88-92

12. WH Minnick, Gas Tungsten Arc Welding, Goodheart Willcox co., (1995)

13. RW Ttulanka, SS Dehankar. Automation in Sheet Metal TIG Welding Process: A Case Study, 7 (4) (2013), 3077-3083

14. Catalogue India mart, (2014)

15. AK Hussain, A Lateef, M Javed, T Pramesh, Influence of welding speed on tensile strength of welded joint in TIG welding process. International Journal of Applied Engineering Research, 3(1) (2010), 26-32

16. A Pai, I Sogalad, SK Albert, P Kumar, TK Mitra,S Basavarajappa, Comparison of Microstructure and Properties of Modified 9Cr-1Mo Welds Produced by Narrow Gap Hot Wire and Cold Wire Gas Tungsten Arc Welding Processes. International Conference on Advances in Manufacturing and Material Engineering AMME. Procedia Material Science, 5 (2014), 1482-1491

17. M Dal, PL Masson, M Carin, A model comparison to predict heat transfer during spot GTA welding. International Journal of Thermal Sciences, 75 (2014), 54-64

18. Z Guang-jun, L Xue-song, WU Lin, Physics characteristics of coupling arc of twin-tungsten TIG welding, 16 (2006), 813-817 